\title{
Multi Criteria Decision Making Problem with Soft Expert Set
}

\author{
I. Arockiarani \\ Department Of Mathematics \\ Nirmala College For Women Coimbatore
}

\author{
A. Arokia Lancy \\ Research Scholar \\ Nirmala College For Women, Coimbatore
}

\begin{abstract}
In this paper, a decision making problem has been discussed with soft expert set and the effectiveness of the result is verified using matrix models and AHP technique.
\end{abstract}

\section{Keywords}

Soft expert set, agree - soft expert set, disagree - soft expert set, RTD matrix, CETD matrix, AHP technique.

\section{INTRODUCTION}

In 1999 , Molodtsov [7] initiated the theory of soft sets as a new mathematical tool to deal with uncertainties while modelling the problems in Engineering Physics, Computer science, Economics, Social Sciences and Medical Sciences . Maji et al [6] presented an application of soft sets in decision making problems and studied basic notions of soft set theory.

Many researchers have studied this theory and they created models to solve problems in decision making. But most of these models deal with only one opinion (or) with only one expert. This causes a problem with the user when questioners are used for the data collection. Alkhazaleh and Salleh [13] defined soft expert set and created a model in which the user can know the opinion of the experts in the model without any operations.

The essence of the paper is to obtain a decision for a day- today life problem with the help of soft expert set and the effectiveness of the same problem is verified with the help of Combined Effect Time Dependent Data (CETD) Matrix and it is checked for consistency through Analytic Hierarchy Process (AHP).

\section{PRELIMINARIES}

Let $\mathrm{U}$ be the universe, $\mathrm{E}$ be the set of parameters and $\mathrm{X}$ a set of experts (agents). Let $\mathrm{O}$ be the set of opinions , $\mathrm{Z}=\mathrm{ExXxO}$, and $\mathrm{A} \subseteq \mathrm{Z}$.

\section{Definition 2.1}

A pair $(F, A)$ is called a soft expert set over $U$, where $F$ is a mapping given by $\mathrm{F}: \mathrm{A} \rightarrow \mathrm{P}(\mathrm{U})$, where $\mathrm{P}(\mathrm{U})$ denotes the power set of $\mathrm{U}$.

\section{Definition 2.2}

For two soft expert sets (F,A) and (G,B) over $\mathrm{U},(\mathrm{F}, \mathrm{A})$ is called a soft expert subset of (G,B) if (i) $\mathrm{A} \subseteq$ B (ii) for all

$\mathrm{e}^{\in} \mathrm{B}, \mathrm{F}(\mathrm{e}) \subseteq \mathrm{G}(\mathrm{e})$. This relationship is denoted by (F,A) $\subseteq$ $(\mathrm{G}, \mathrm{B})$. In this case $(\mathrm{G}, \mathrm{B})$ is called the soft expert super set of (F,A).

\section{Definition 2.3}

Two soft expert sets $(F, A)$ and $(\mathrm{G}, \mathrm{B})$ over $\mathrm{U}$ are said to be equal if $(F, A)$ is soft expert subset of $(G, B)$ and $(G, B)$ is called a soft expert subset of $(\mathrm{F}, \mathrm{A})$.

\section{Definition 2.4}

Let $\mathrm{E}$ be a set of parameters and $\mathrm{X}$, a set of experts . The NOT set of $Z=E \times X \times O$ denoted by $\neg Z$, is defined by $\neg Z=\left\{\left(\neg e_{i}, x_{j}, o_{k}\right) \forall i, j, k\right\}$ where $\neg e_{i}$ is not $e_{i}$.

\section{Definition 2.5}

The complement of a soft expert set $(\mathrm{F}, \mathrm{A})$ is denoted by $(\mathrm{F}, \mathrm{A})^{\mathrm{c}}$ and is defined by $(\mathrm{F}, \mathrm{A})^{\mathrm{c}}=\left(\mathrm{F}^{\mathrm{c}}, \neg \mathrm{A}\right)$ where $\mathrm{F}^{\mathrm{c}}$ : $\neg \mathrm{A} \rightarrow \mathrm{P}(\mathrm{U})$ is a mapping given by $\mathrm{F}^{\mathrm{c}}(\mathrm{e})=\mathrm{U}-\mathrm{F}(\mathrm{e})$, $\forall \mathrm{e} \in \neg \mathrm{A}$.

\section{Definition 2.6}

An agree- soft expert set $(F, A)_{1}$, over $U$ is a soft expert subset of $(\mathrm{F}, \mathrm{A})$ is defined as

$$
(\mathrm{F}, \mathrm{A})_{1}=\left\{\mathrm{F}_{1}(\mathrm{e}): \mathrm{e} \in \operatorname{ExXx}\{1\}\right\} .
$$

\section{Definition 2.7}

An disagree- soft expert set $(\mathrm{F}, \mathrm{A})_{0}$, over $\mathrm{U}$ is a soft expert subset of $(\mathrm{F}, \mathrm{A})$ is defined as

$(\mathrm{F}, \mathrm{A})_{0}=\left\{\mathrm{F}_{0}(\mathrm{e}): \mathrm{e} \in \operatorname{ExXx}\{0\}\right\}$

\section{Proposition 2.8}

If $(\mathrm{F}, \mathrm{A})$ is a soft expert set over $\mathrm{U}$, then

$$
\begin{aligned}
& \text { (i) }\left((F, A)^{c}\right)^{c}=(F, A)\left(\text { ii) }(\mathrm{F}, \mathrm{A})_{1}^{\mathrm{c}}=(F, A)_{0}\right. \\
& \text { (iii) }(\mathrm{F}, \mathrm{A})_{0}^{\mathrm{c}}=(F, A)_{1}
\end{aligned}
$$

\section{Definition 2.9}

The union of two soft expert sets of $(F, A)$ and $(G, B)$ over $U$ denoted by $(F, A) \widetilde{U}(G, B)$ is the soft expert set $(H, C)$, where $\mathrm{C}=\mathrm{A} \cup \mathrm{B}$ and for all $\mathrm{e} \in \mathrm{C}, \mathrm{H}(\mathrm{e})=\mathrm{F}(\mathrm{e})$ if $\mathrm{e} \in \mathrm{A}-\mathrm{B}, \mathrm{G}(\mathrm{e})$ if $\mathrm{e}^{\in} \mathrm{B}-\mathrm{A}$ and $\mathrm{F}(\mathrm{e}) \cup \mathrm{G}(\mathrm{e})$ if $\mathrm{e} \in \mathrm{A} \cap \mathrm{B}$.

\section{Definition 2.10}

The intersection $(\mathrm{H}, \mathrm{C})$ of two soft expert sets $(\mathrm{F}, \mathrm{A})$ and $(\mathrm{G}, \mathrm{B})$ over a common universe $\mathrm{U}$, denoted $(\mathrm{F}, \mathrm{A}) \widetilde{\mathrm{n}}(\mathrm{G}, \mathrm{B})$, is defined as $\mathrm{C}=\mathrm{A} \cap \mathrm{B}$, and for all $\mathrm{e} \in \mathrm{C}, \mathrm{H}(\mathrm{e})=\mathrm{F}(\mathrm{e})$ if $\mathrm{e} \in \mathrm{A}-\mathrm{B}, \mathrm{G}(\mathrm{e})$ if $\mathrm{e} \in \mathrm{B}-\mathrm{A}$ and $\mathrm{F}(\mathrm{e}) \cap \mathrm{G}(\mathrm{e})$ if $\mathrm{e} \in \mathrm{A} \cap \mathrm{B}$. 


\section{Definition 2.11}

If $(\mathrm{F}, \mathrm{A})$ and $(\mathrm{G}, \mathrm{B})$ are two soft expert sets over $\mathrm{U}$, then $(\mathrm{F}, \mathrm{A})$ OR $(\mathrm{G}, \mathrm{B})$ is defined as

$(F, A) \vee(G, B)=(O, A x B)$,

where $O(\alpha, \beta)=F(\alpha) \tilde{\cup} G(\beta), \forall(\alpha, \beta) \in A x B$.

\section{An Application Via Soft Expert Sets}

In this section we give an application of the soft expert set in a decision making problem. The problem we consider is as follows. Suppose that a college wants to select a student for the "Best outgoing student award" and there are four nominees who form the universe $U=\left\{\mathrm{s}_{1}, \mathrm{~s}_{2}, \mathrm{~s}_{3}, \mathrm{~s}_{4}\right\}$. Let $\mathrm{X}=\{$ $\mathrm{p}, \mathrm{q}, \mathrm{r}\}$ be a set of expert committee members. This expert committee considers a set of parameters

$\mathrm{E}=\{$

$\left.\mathrm{e}_{1}, \mathrm{e}_{2}, \mathrm{e}_{3}\right\}$, where the parameters $\mathrm{e}_{\mathrm{i}},(\mathrm{i}=1,2,3)$ stands for the academic performance, extra-curricular activities, good conduct respectively.

Suppose $(\mathrm{F}, \mathrm{Z})=\left\{\left(\left(\mathrm{e}_{1}, \mathrm{p}, 1\right),\left\{\mathrm{s}_{1}, \mathrm{~s}_{2}, \mathrm{~s}_{4}\right\}\right)\right.$,

$\left(\left(\mathrm{e}_{1}, \mathrm{q}, 1\right),\left\{\mathrm{s}_{1}, \mathrm{~s}_{4}\right\}\right),\left(\left(\mathrm{e}_{1}, \mathrm{r}, 1\right),\left\{\mathrm{s}_{3}, \mathrm{~s}_{4}\right\}\right)$,

$\left(\left(e_{2}, p, 1\right),\left\{s_{4}\right\}\right),\left(\left(e_{2}, q, 1\right),\left\{s_{1}, s_{3}\right\}\right),\left(\left(e_{2}, r, 1\right),\left\{s_{1}, s_{2}, s_{4}\right\}\right)$,

$\left(\left(e_{3}, p, 1\right),\left\{s_{3}, s_{4}\right\}\right),\left(\left(e_{3}, q, 1\right),\left\{s_{1}, s_{2}\right\}\right),\left(\left(e_{3}, r, 1\right),\left\{s_{4}\right\}\right)$,

$\left(\left(\mathrm{e}_{1}, \mathrm{p}, 0\right),\left\{\mathrm{s}_{3}\right\}\right),\left(\left(\mathrm{e}_{1}, \mathrm{q}, 0\right),\left\{\mathrm{s}_{2}, \mathrm{~s}_{3}\right\}\right),\left(\left(\mathrm{e}_{1}, \mathrm{r}, 0\right),\left\{\mathrm{s}_{1}, \mathrm{~s}_{2}\right\}\right)$,

$\left(\left(e_{2}, p, 0\right),\left\{s_{1}, s_{2}, s_{3}\right\}\right),\left(\left(e_{2}, q, 0\right),\left\{s_{2}, s_{4}\right\}\right),\left(\left(e_{2}, r, 0\right),\left\{s_{3}\right\}\right)$,

$\left.\left(\left(\mathrm{e}_{3}, \mathrm{p}, 0\right),\left\{\mathrm{s}_{1}, \mathrm{~s}_{2}\right\}\right),\left(\left(\mathrm{e}_{3}, \mathrm{q}, 0\right),\left\{\mathrm{s}_{3}, \mathrm{~s}_{4}\right\}\right),\left(\left(\mathrm{e}_{3}, \mathrm{r}, 0\right),\left\{\mathrm{s}_{1}, \mathrm{~s}_{2}, \mathrm{~s}_{3}\right\}\right)\right\}$

In order to arrive at a conclusion, i.e. to select one student for the award, the parameters are given some weight, say $\mathrm{e}_{1}=0.6, \mathrm{e}_{2}=0.4, \quad \mathrm{e}_{3}=1$, the decision can be made by the use of agree matrix as follows :

$$
\left(\begin{array}{llll}
2 & 1 & 1 & 3 \\
2 & 1 & 1 & 2 \\
1 & 1 & 1 & 2
\end{array}\right)
$$

This matrix is framed with the assumption made in $(\mathrm{F}, \mathrm{Z})$. The Average Time Dependent Data (ATD) Matrix obtained is

$\left(\begin{array}{llll}3.33 & 1.67 & 1.67 & 5 \\ 5 & 2.5 & 2.5 & 5 \\ 1 & 1 & 1 & 2\end{array}\right)$

To obtain the Refined Time Dependent Data (RTD) Matrix we use, if $\mathrm{a}_{\mathrm{ij}} \leq\left(\mu_{\mathrm{j}}-\alpha * \sigma_{\mathrm{j}}\right)$ then $\mathrm{e}_{\mathrm{ij}}=-1$

if $\mathrm{a}_{\mathrm{ij}} \in\left(\mu_{\mathrm{j}}-\alpha^{*} \sigma_{\mathrm{j}}, \mu_{\mathrm{j}}+\alpha^{*} \sigma_{\mathrm{j}}\right)$ then $\mathrm{e}_{\mathrm{ij}}=0$

if $\mathrm{a}_{\mathrm{ij}} \geq\left(\mu_{\mathrm{j}}+\alpha^{*} \sigma_{\mathrm{j}}\right)$ then $\mathrm{e}_{\mathrm{ij}}=1$

With values of $\alpha$ as $0.5,0.25,0.75$ the following RTD's were obtained

$$
\begin{aligned}
& \left(\begin{array}{rrrc}
0 & 0 & 0 & 1 \\
1 & 1 & 1 & 1 \\
-1 & -1 & -1 & -1
\end{array}\right),\left(\begin{array}{rrrc}
0 & 0 & 0 & 1 \\
1 & 1 & 1 & 1 \\
-1 & -1 & -1 & -1
\end{array}\right), \\
& \left(\begin{array}{rrrr}
0 & 0 & 0 & 0 \\
1 & 0 & 0 & 0 \\
-1 & -1 & -1 & -1
\end{array}\right)
\end{aligned}
$$

The CETD matrix formed with the above obtained RTD is

$$
\left(\begin{array}{rrrc}
0 & 0 & 0 & 2 \\
3 & 2 & 2 & 2 \\
-3 & -3 & -3 & -3
\end{array}\right)
$$

The column sum matrix is $\left(\begin{array}{llll}0 & -1 & -1 & 1\end{array}\right)$.This matrix gives the result that the student $\mathrm{s}_{4}$ is the best student to be opted for the award.

\section{Verification with AHP technique}

The AHP is a powerful and flexible Multi Criteria Decision Making tool for dealing with complex problems where both qualitative and quantitative aspects are taken into consideration.

The problem of selecting 'A Best Student' is applied again with this technique to verify the result obtained from the soft expert set.

The students are compared using the pairwise comparison scale for AHP preference.

The following tables are framed with Saaty's scale for each of the parameter.,say, $e_{i},(i=1,2,3)$,the academic performance , extra-curricular activities, good conduct respectively. 
Table 1. COMPARISON TABLE FOR $\mathrm{e}_{1}$

\begin{tabular}{|c|l|l|l|l|}
\hline Parameter $\left(e_{1}\right)$ & & & & \\
\hline$S_{1}$ & $S_{1}$ & $S_{2}$ & $S_{3}$ & $S_{4}$ \\
\hline$S_{2}$ & 1 & 2 & 2 & $1 / 2$ \\
\hline$S_{3}$ & $1 / 2$ & 1 & 1 & $1 / 3$ \\
\hline$S_{4}$ & $1 / 2$ & 1 & 1 & $1 / 3$ \\
\hline
\end{tabular}

The above table is used to find the eigen vector $A_{i j}$ by dividing the values using the column sum .

\begin{tabular}{|c|l|l|l|l|l|}
\hline $\begin{array}{l}\text { Parameter } \\
\left(\mathrm{e}_{1}\right)\end{array}$ & $\mathrm{S}_{1}$ & $\mathrm{~S}_{2}$ & $\mathrm{~S}_{3}$ & $\mathrm{~S}_{4}$ & $\mathrm{~A}_{\mathrm{ij}}$ \\
\hline $\mathrm{S}_{1}$ & 0.25 & 0.2857 & 0.2857 & 0.2308 & 0.2631 \\
\hline $\mathrm{S}_{2}$ & 0.125 & 0.1429 & 0.1429 & 0.1538 & 0.1412 \\
\hline $\mathrm{S}_{3}$ & 0.125 & 0.1429 & 0.1429 & 0.1538 & 0.1412 \\
\hline $\mathrm{S}_{4}$ & 0.5 & 0.4286 & 0.4286 & 0.4615 & 0.4547 \\
\hline
\end{tabular}

The corresponding eigen values are $(1.0553,0.5655,0.5655$, 1.8281) which shows $\mathbf{S}_{4}$ as the best student. However the consistency is checked with the consistency test and consistency ratio.

Consistency Test

$C I=\frac{\lambda-n}{n-1}$, where $\mathrm{n}$ is the dimension of the matrix,

$\lambda$ is the eigenvalue

$$
\mathrm{Cl}=\frac{1.8281-4}{4-1}=-0.724
$$

Consistency Ratio

$C R=\frac{C I}{R I}$, where $\mathrm{RI}$ is the Random indices corresponding to the dimension of the matrix.

$\mathrm{CR}=-0.724 / 0.9=-0.8044$.

The consistency ratio is acceptable if it does not exceed 0.10 . Hence the judgment that the student $S_{4}$ as the best student for the award is acceptable.

The following table shows the comparisons with the other two parameters $\mathbf{e}_{2}$ and $\mathbf{e}_{3}$
COMPARISON TABLE FOR e2:

\begin{tabular}{|l|l|l|l|l|}
\hline Parameter $\left(\mathrm{e}_{2}\right)$ & & & & \\
& $\mathrm{S}_{1}$ & $\mathrm{~S}_{2}$ & $\mathrm{~S}_{3}$ & $\mathrm{~S}_{4}$ \\
\hline $\mathrm{S}_{1}$ & 1 & 2 & 2 & $1 / 2$ \\
\hline $\mathrm{S}_{2}$ & $1 / 2$ & 1 & 1 & $1 / 2$ \\
\hline $\mathrm{S}_{3}$ & $1 / 2$ & 1 & 1 & $1 / 2$ \\
\hline $\mathrm{S}_{4}$ & 1 & 2 & 2 & 1 \\
\hline
\end{tabular}

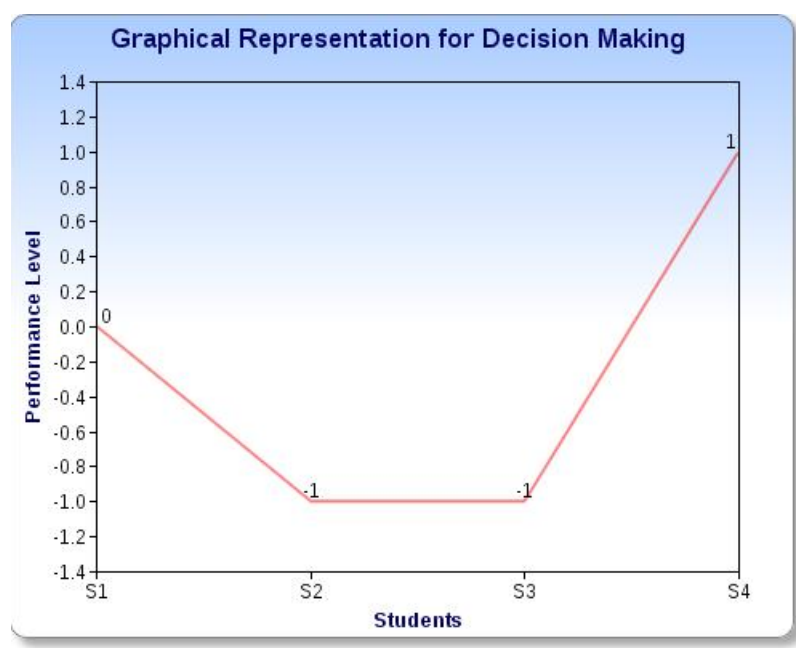

COMPARISON TABLE FOR e3:

\begin{tabular}{|l|l|l|l|l|}
\hline Parameter $\left(\mathrm{e}_{3}\right)$ & & & & \\
& $\mathrm{S}_{1}$ & $\mathrm{~S}_{2}$ & $\mathrm{~S}_{3}$ & $\mathrm{~S}_{4}$ \\
\hline $\mathrm{S}_{1}$ & 1 & 1 & 1 & $1 / 2$ \\
\hline $\mathrm{S}_{2}$ & 1 & 1 & 1 & $1 / 2$ \\
\hline $\mathrm{S}_{3}$ & 1 & 1 & 1 & $1 / 2$ \\
\hline $\mathrm{S}_{4}$ & 2 & 2 & 2 & 1 \\
\hline
\end{tabular}

The corresponding Eigen vectors for $\left(\mathbf{e}_{2}\right)$ and $\left(\mathbf{e}_{3}\right)$ are

$\left(\begin{array}{l}0.3333 \\ 0.1667 \\ 0.1667 \\ 0.3333\end{array}\right),\left(\begin{array}{l}0.2 \\ 0.2 \\ 0.2 \\ 0.4\end{array}\right)$


The corresponding Eigen values for $\left(\mathbf{e}_{2}\right)$ and $\left(\mathbf{e}_{3}\right)$ are $\left(\begin{array}{llll}1.3334 & 0.6667 & 0.6667 & 1.3334\end{array}\right)$ and $\left(\begin{array}{llll}0.8 & 0.8 & 0.8 & 1.6\end{array}\right)$

Fig 1: The above is a graphical representation support the decision obtained by soft expert set.

\section{Conclusion:}

A decision making problem is discussed with the help of soft expert set and its effectiveness is compared with matrix model, with a graphical representation and the decision is model, with a graphical representation and the decision is checked for its consistency using the AHP technique

\section{REFERENCES}

[1] Aktas,H. and Cagman,N., 2007 Soft Sets and Soft Groups Inf .Sci. 2726-2735.

[2] Dodd, F. and Donegan, H. 1995 Comparison of prioritization techniques using interhierarchy map. Journal of Operations Research Society 46(4): 492-498..

[3] Hwang, C.L. and Yoon , K. 1981. Multiple Attribute Decision Making Methods and Applications, Springer, Berlin Heidelberg

[4] Levary, R.R and Wan , K., 1998 A Simulation Approach for Handling Uncertainity in the Analytic Hierarchy Process . European Journal of Operations Research Society 106(1),116-122.

[5] Liberatore, M.J and Nydick , R.L., 2008 The Analytic Hierarchy Processin Medical and Health Care Decision Making: A Literature Review 108(1)294-307.

[6] Maji. P.K ., Biswas . R and Roy A.R., 2003 Soft Set Theory, Computers and Mathematics with Applications 555-562

[9] Sabir Hussain and Mohammad Ahmad Alghamdi, 2012, On Soft Expert Topological Spaces, Springer Plus.

[10] Shabir, M and Naz, M., 2011 On Soft Topological Spaces, Computers and Mathematics with Applications 61(7) 1786-1799.
The consistency ratio $\mathrm{CR}$ for the parameters $\mathrm{e}_{2}$ and $\mathrm{e}_{3}$ are 0.9876 and -0.8889 respectively. Both the vales are less than 0.1. Hence the student $S_{4}$ can be selected for 'Best Student Award'

[7] Molodtsov.D.,1999 Soft Set Theory-First results Computers and Mathematics with Applications ,19-31

[8] Pawlak.Z 1982, Rough Sets, International Journal of Computer Science, 341 - 356

[11] Satty T.L, 1980 The Analytic Hierarchy Process: Planning, Priority Setting, Resource Allocation . Mc Graw Hill , Newyork .

[12] Satty T.L, 1977 , A scaling method for priorities in hierarchial structures , Journal of Mathematical Psychology, 15(3):234-281.

[13] Shawkat Alkhazaleh and Abdul Razak Salleh, 2011, Soft Expert Sets, Research Article, Advances in Decision Sciences.

[14] Vahidnia,M.H, Aleshikh, A.A and Alimohammadi, A., 2009, Hospital site selection using fuzzy AHP and its Derivatives, Jouirnal Of Environmental Management, 90(10),3048-3056.

[15] Victor Devadoss., A and Clement Joe Anand .M , 2012, Dimensions of Personality of Women in Chennai using CETD Matrix, International Journal of Computer Applications50(5)

[16] Wang ,C, Lin, L and Wu, S., 2012, An uncertain decision making model An application to AHP, International Jo urnal of Advanced Research in Computer Science, $3(2)$

[17] Wand Y.J and Lee . H.S ,2007, Generalising TOPSIS for fuzzy multiple criteria group decision making, Journal of Computers And Mathematics , 53(1), 1762-1772. 